\title{
Mapping stakeholder values for coastal zone management
}

\author{
A. Ruiz-Frau ${ }^{1, *}$, G. Edwards-Jones ${ }^{2}$, M. J. Kaiser ${ }^{1}$ \\ ${ }^{1}$ School of Ocean Sciences, College of Natural Sciences, Bangor University, LL59 5AB, UK \\ ${ }^{2}$ School of the Environment, Natural Resources and Geography, College of Natural Science, Bangor University, LL57 2UW, UK
}

\begin{abstract}
There is a growing recognition of the need to incorporate multiple values in environmental management plans. While biological and, increasingly, economic values are considered in the design of management strategies, community or stakeholder values are not often taken into account. We mapped stakeholders' values for marine ecosystems and assessed their preferences for the location and type of marine protected areas (MPAs) around the coast of Wales (UK). Stakeholders were chosen to represent a comprehensive range of interests in the marine environment. Fourteen different types of value were identified by stakeholders. The spatial distribution of the different values attached to the marine environment was ascertained; this revealed the existence of areas where multiple values overlapped. Results indicated that areas perceived as ecologically important also possessed high heritage and leisure values. When locating MPAs, stakeholders balanced conservation needs with societal demands by protecting areas identified as ecologically important while avoiding those areas where restrictions could have a considerable impact on society. Data suggested a preference for MPAs that permitted a range of adequately regulated anthropogenic activities. The distribution of stakeholders' values and the identification of areas of multiple value help managers to understand the potential consequences of particular management strategies, and allow them to be aware of the location of areas where greater consideration is required when designing management plans, as multiple interests may overlap. Thus, mapping stakeholders' values in the marine environment provides a useful tool for identifying areas better suited for specific management regulations and for the development of comprehensive marine spatial plans, as these require the understanding of the spatial heterogeneity of the different ecosystem components including both ecological and human elements.
\end{abstract}

KEY WORDS: Ecosystem service $\cdot$ Marine spatial planning $\cdot$ Marine protected area $\cdot$ Community values

\section{INTRODUCTION}

There is an increasing need to incorporate multiple values (i.e. economic, social and cultural) into conservation and environmental management plans (Cowling et al. 2008, Naidoo et al. 2008). Strategy documents such as the Millennium Ecosystem Assessment (MEA) have highlighted the necessity to take into account the intrinsic values associated with ecosystems and also to adopt a comprehensive approach that encompasses a wider range of values, including the local, cultural and economic values that stem from the relationship between people and nature (MEA 2005). However, whilst ecological, and latterly economic values (Naidoo et al. 2008), are considered in the definition and design of environmental management plans, community or stakeholder values are not always considered (Alessa et al. 2008, Raymond et al. 2009, Bryan et al. 2010). If these values are to be incorporated into spatial management plans, it is essential that they possess a spatial component so that they can be integrated with spatially defined biophysical, ecological and economic data. In addition to facilitating the integration of information, Zube (1987) suggested several advantages associated with mapping community values; firstly it permits the identification of places people value and the reasons 
why they value them, thus allowing managers to become aware of the need to give particular areas extra consideration when designing management plans. Secondly, it identifies areas of potential conflict between user groups in cases where multiple user groups value an area for potentially conflicting reasons; and thirdly, it helps managers understand the potential consequences that alternative management scenarios can have on the wider environment and on society.

In terrestrial systems, several studies have mapped community values of the natural environment using different approaches. For example, values associated with urban natural areas, such as parks and green areas, have been mapped in Finland (Tyrvainen et al. 2007), while other studies have elucidated the values people ascribe to publicly owned lands (Brown \& Reed 2000, Alessa et al. 2008, McIntyre et al. 2008). A variety of value typologies have been used in these studies; however, some of the typologies focused only on particular sets of values, such as recreational values, and thus did not have the scope to capture the wider array of values that can be associated with the natural environment (McIntyre et al. 2008). Brown (2004) developed a landscape value methodology to map and measure a wider range of landscape values which included recreational, aesthetic, economic, cultural and biodiversity values. Whilst this methodology sought to understand a range of values from the social perspective, it failed to capture the biophysical aspects of value. Raymond et al. (2009) provided a potential framework for understanding this broader set of values by integrating Brown's (2004) typology with the concept of natural capital and ecosystem services established by the MEA (2005), thereby offering the possibility to value other aspects of the environment such as the provision of regulating or supporting services.

Such an approach to mapping community values is lacking in the marine environment despite its potential value to accomplish successful marine spatial planning (MSP). The development of comprehensive MSP requires an understanding of the spatial heterogeneity of different ecosystem components, including both ecological and human elements. Marine protected areas (MPAs) are among the most important management and conservation tools available within a framework of MSP and have been advocated as an essential part for achieving global marine conservation targets (UN 2002, OSPAR Commission 2003, CBD 2008). For MPAs to be successful in achieving their conservation objectives, they need to be designed with biological principles as a primary design criterion (Roberts et al. 2003), but they also need to have community support in order to ensure user compliance (Moore et al. 2004). Despite having recognised the latter as an important factor for success, community values are not always considered during the MPA design process, which remains dominated by biological issues.

The aim of our study was to elicit and spatially define community values for the marine environment. This was achieved by adapting the value typology of Raymond et al. (2009) to the marine environment. Whilst Raymond et al. (2009) used MEA's classification for ecosystem goods and services (EGS), we utilised an adaptation of MEA's EGS to the marine environment (Beaumont et al. 2007). Our study focused on Wales, UK, where the Welsh Assembly Government has adopted a Marine and Coastal Access Act through which it is committed to 'establishing an ecologically coherent, representative and well-managed network of marine protected areas' taking into account 'environmental, social and economic criteria' by 2012 (DEFRA 2009). Although comprehensive information is available for the distribution of biophysical and ecological factors, no information exists on the social values associated with the marine environment in Wales. We sought to inform the decision-making process regarding the design of MPAs in Wales by providing key insights into the values held by different stakeholder groups with an interest in the marine environment. This was achieved by gathering information on the values and benefits derived from the marine environment by different stakeholder groups and by defining the spatial distribution of those values such that they could be incorporated into marine spatial management plans. Stakeholder views on the preferred location and design of MPAs and their associated management were also investigated.

\section{MATERIALS AND METHODS}

Study area. Wales has a coastline of $\sim 1300 \mathrm{~km}$, and an area of $\sim 16000 \mathrm{~km}^{2}$ lies within Welsh territorial waters (Fig. 1). The majority of the Welsh population is concentrated in coastal areas, where the marine environment offers the opportunity for a wide range of uses such as commercial fisheries, tourism, energy provision, recreation and shipping. Therefore, a variety of stakeholder groups exists with a wide range of interests and values attached to the marine environment.

Stakeholder sample. To achieve a comprehensive representation of community views, representatives of various stakeholder groups with different interests in the marine environment were interviewed. In order to do this, members of the Wales Maritime and Coastal Partnership (WMCP) were approached. The WMCP is formed of representatives of maritime and coastal interests in Wales encompassing 26 organisations drawn from the public, private and voluntary sector. For the purpose of our study, only those organisations 


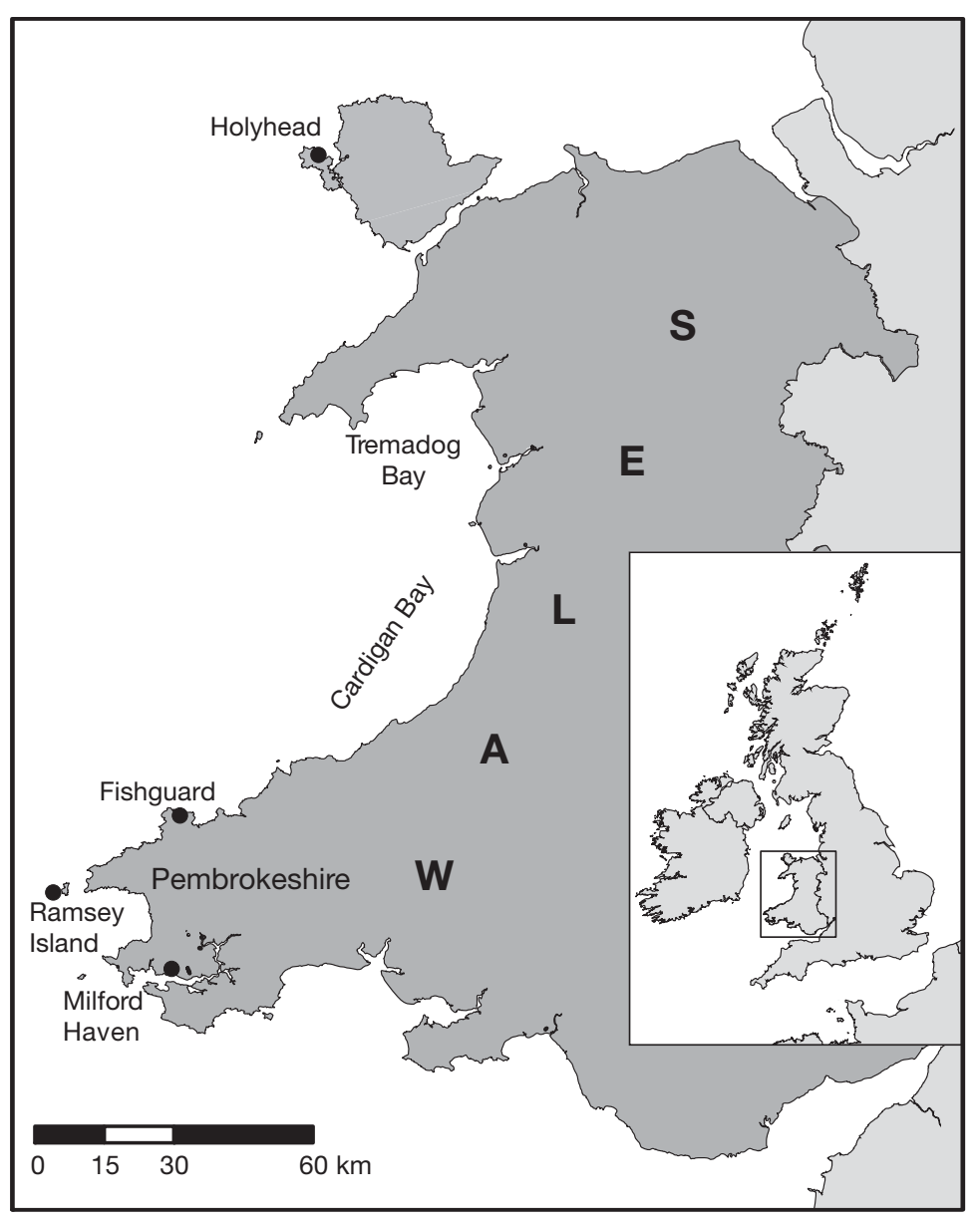

Fig. 1. Study region

with direct involvement in the marine environment were approached (24 organisations). Of these 24 organisations, 4 declined to participate in the study, and no response was received from a further 6, despite several attempts to contact them. Thus a total of 14 organisations took part in the study. Whenever possible, 2 members from each organisation were interviewed separately (total number of individuals interviewed $=22$; Table 1 ) .

The individuals interviewed in the study were members of organisations that deal with pan-Wales issues on a regular basis; therefore, study participants had a sound knowledge of the coast of Wales. Additionally, in order to achieve a spatially balanced collection of information, an equal number of representatives were interviewed in the areas of North and South Wales.

Interview design. In-depth interviews were conducted with the participants between January and June 2010. Interviews followed an open-ended format with full probing. Meetings generally occurred in the interviewee's work place and lasted for around $1 \mathrm{~h}$. All interviews focused around 2 main questions: (1) which areas of the Welsh marine environment the participant thought provided the most important benefits to society and why; and (2) which areas of the Welsh marine environment would the participant like to see protected from certain human uses.

Mapping of stakeholder values. The interview was divided into 2 parts. In the first part, participants were asked to indicate places of value to them by arranging $1 \mathrm{~cm}$ wooden cubes on the marine areas of a 1:500 000 A3 map of Wales. Each cube covered an area of $100 \mathrm{~km}^{2}$ on the map. A $10 \times$ $10 \mathrm{~km}$ grid was superimposed on the map, and participants were requested to fit the cubes onto the grid cells. Before arranging the cubes on the map, participants were introduced to the benefits society obtains from the marine environment according to the MEA EGS classification adapted by Beaumont et al. (2007) for the marine environment. As part of this process, participants were given a laminated card with the adapted MEA classification to use as reference (Table 2); however participants were not restricted to the given typology and they could expand on it if they felt that certain aspects were not covered. Participants were given a maximum of 30 cubes, equivalent to $14 \%$ of the total available cells. Participants were then asked to place the cubes on those cells of the map where they thought nature provided the most important benefits to society. Once the cubes were arranged on the map, participants were asked to indicate the reasons why they considered the selected cells to be important and the type of benefits or values they thought society obtained from those areas.

Table 1. Classification of study participants by organisation type, number of participants by organisation type and number of individuals they represent. na: not applicable, NGO: nongovernment organisation

\begin{tabular}{|lcc|}
\hline $\begin{array}{l}\text { Stakeholder organisation } \\
\text { type }\end{array}$ & $\begin{array}{c}\text { No. of } \\
\text { participants }\end{array}$ & $\begin{array}{c}\text { Membership } \\
\text { representation }\end{array}$ \\
\hline Business \& industry & 4 & na \\
Academic research & 3 & na \\
Commercial fisheries & 3 & $435^{\mathrm{a}}$ \\
Heritage & 3 & 100000 \\
NGO \& voluntary sector & 2 & 1000 \\
Environmental public bodies & 3 & na \\
Recreational sector & 4 & 26000 \\
aNo. of vessels represented by the Welsh Federation of \\
Fishermen's Association Ltd
\end{tabular}


Table 2. Goods and services provided by the marine environment (adapted from Beaumont et al. 2007)

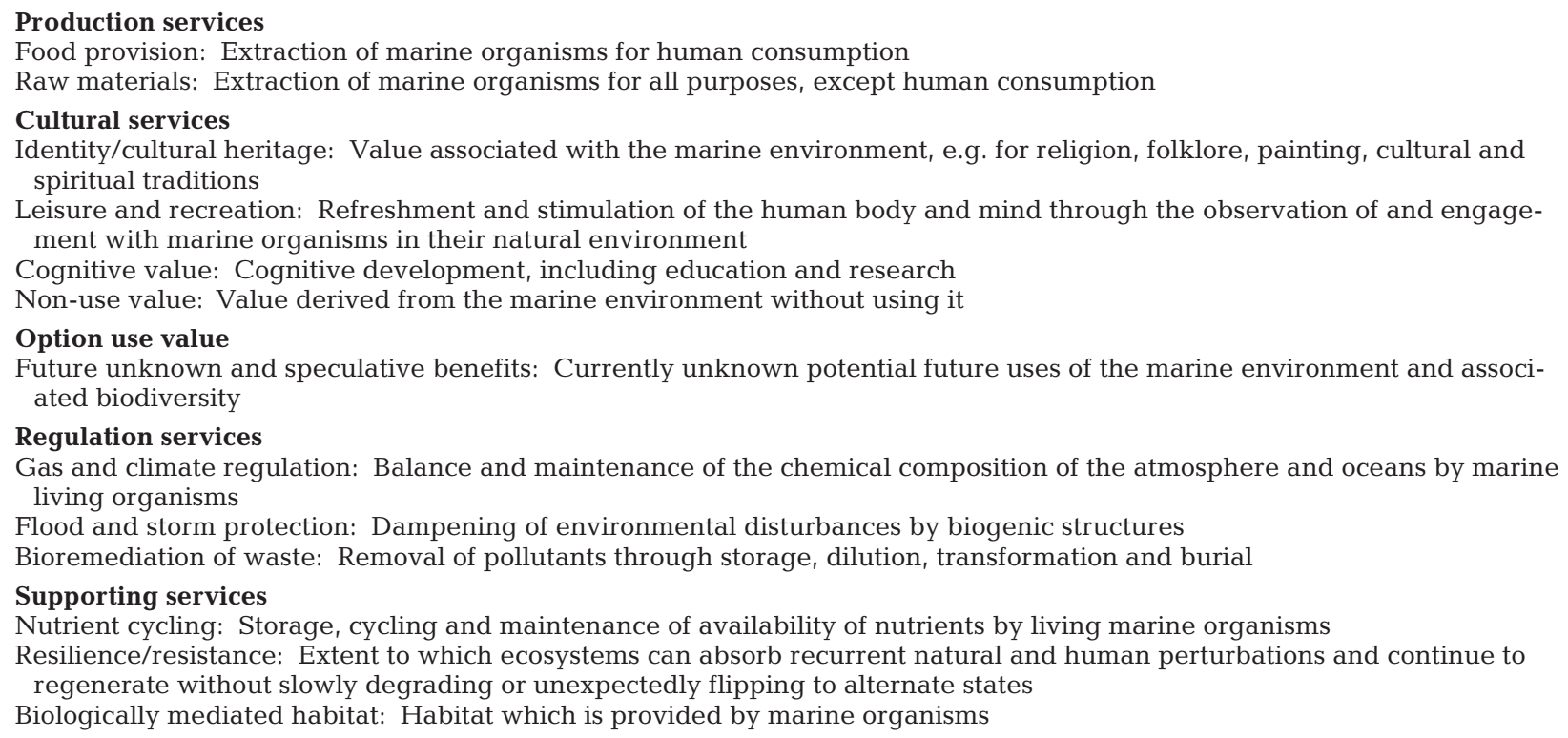

The second part of the exercise was concerned with the establishment and location of MPAs in Wales. Participants were briefed on the current conservation policy situation in Wales. They were asked to indicate those cells where they would like to see some type of protection or restriction in the marine environment. To create priority in the selection of areas, the exercise was divided into 3 subtasks; first, participants were given 10 cubes to place on the map, so that only 10 cells could be selected for protection. Once the cubes were arranged on the map, participants were then given another 10 cubes and once these were arranged, an extra 10 cubes were given. To be able to identify the cells selected through the different subtasks, each of the 3 sets of cubes had a different colour. After each subtask, participants were asked to indicate the reasons behind their selection and to state the type of protection they would like to see in place for each of the selected cells. Participants could choose among 3 levels of protection: (1) closed access areas, where no human activities were allowed, (2) areas where nonextractive recreational activities were allowed, and (3) areas where restricted recreational and commercial fishing were permitted.

Data analysis. Digital pictures of the participant's maps were taken after each exercise, and the results were digitised using geographic information system (GIS) software (ArcGIS 9.2, ESRI). Additionally, a database was created with the attribute information associated with each of the cells on the map. This database was linked to the spatial information stored in the GIS. The percentage of participants and the number of times each cell was identified as an important provider of a particular benefit, or was selected for protection, was recorded and used in subsequent spatial analyses.

The assessment of potential spatial relationships was undertaken using 2 different types of analyses. First, Pearson's correlations were used to identify geographic relationships between pairs of benefits (Mitchell 2005). Second, the level of spatial aggregation for each of the benefits was analysed using Local Moran's $I$, which allows for the identification of clusterings of similar values (high or low) by analysing how much each cell is similar or dissimilar to its neighbours (Mitchell 2005). The statistical significance of Moran's $I$ at a certain confidence level is calculated using the $Z$-score. High values of Moran's I indicate high clustering, values around 0 indicate no clustering, and negative values indicate dispersion. Three maps were produced for each of the perceived benefits. Local Moran's I was mapped to show the location of clusters of similar values, Z-score maps were produced to indicate which of the clusters were significant at a $95 \%$ confidence level, and a third map that showed the percentage of times each cell was selected for a particular benefit was produced to indicate whether the clusters comprised high or low values.

\section{RESULTS}

\section{Spatial distribution of values}

The nature of stakeholders' values and their spatial distribution were examined for the coast of Wales. 
Participants identified 14 different types of societal benefits or values derived from the marine environment. To classify the different benefits, interviewees used the card given to them as a reference, and additionally, they expanded on the typology of benefits and included other reasons for valuing certain areas of the marine environment such as the geological value of an area or the value attached to a particular zone due to its conservation designation. The majority of participants identified tourism and recreation, food provision, industrial opportunities and ecological importance as the most cited values derived from the marine environment (Table 3). The opportunities offered by the marine environment for recreation and tourism were perceived as the most important benefit for society, as 'tourism and recreation' values were assigned the greatest number of cubes when compared to the other potential values. 'Ecological value' was the benefit that received the second highest number of cubes and was mentioned by $83 \%$ of participants. Only those participants from the academic sector or the environmental public bodies specifically mentioned the supporting and regulating benefits provided by the marine environment; this may relate to the level of expertise of the interviewees. However, it became clear from the interviews that other participants included these benefits under the broader term of 'ecological value'.

Benefits derived from marinas and from the 3 main commercial ports in Wales (Holyhead, Fishguard and Milford Haven, Fig. 1) were perceived as 'industrial values' and were mentioned by a high proportion of participants; $\sim 70 \%$ of participants referred to these during the interviews. Participants also viewed the marine environment as an important source of energy supply. Areas off the north coast of Wales were men-

Table 3. Stakeholder values, number of cubes allocated to each value (see 'Materials and methods-Mapping of stakeholder values' for details) and number of participants who mentioned each of them

\begin{tabular}{|lcc|}
\hline Value & $\begin{array}{c}\text { No. of } \\
\text { cubes }\end{array}$ & $\begin{array}{c}\text { No. of } \\
\text { participants }\end{array}$ \\
\hline Tourism/leisure/recreation & 416 & 20 \\
Ecological value & 332 & 19 \\
Food provision (fisheries) & 124 & 16 \\
Industrial value & 104 & 16 \\
Identity/heritage & 99 & 9 \\
Existing conservation designations & 44 & 3 \\
Supporting services & 44 & 3 \\
Cognitive value & 30 & 4 \\
Energy provision & 21 & 7 \\
Geological value & 18 & 2 \\
Regulation services & 16 & 3 \\
Option value & 12 & 2 \\
High population & 4 & 1 \\
Total & 637 & 22 \\
\hline
\end{tabular}

tioned as important for wind energy and areas in the south and south west coast were pointed out as potential suppliers of tidal energy.

GIS maps were created for the spatial distribution of the benefits most frequently mentioned by participants (Fig. 2). The mapping of $Z$-scores indicated the existence of significant clusters of high values for several of the benefits (i.e. areas selected by a high percentage of participants). For most of the benefits, significant clusters tended to be located around the same areas (Pembrokeshire coast, Cardigan Bay and Tremadog Bay, Fig. 1), suggesting that certain areas were perceived as providers of multiple benefits. The similarity of the spatial distribution for some of the benefits was further confirmed by strong positive spatial correlations between some pairs of benefits (Table 4). For instance, the distribution of areas with an associated ecological value was strongly correlated with the distribution of areas with associated recreational benefits (Pearson $r=0.904)$, identity/heritage values $(r=0.815)$ and fisheries benefits $(\mathrm{r}=0.72)$. A map showing the total number of values assigned to each cell was created, and the presence of significant clusters was identified (Fig. 3a). This map makes it possible to identify ‘hotspot areas' for the provision of values.

\section{Location of MPAs}

The majority of participants $(74 \%)$ used the 30 available cubes for the selection of protected areas. In general, participants supported less restrictive marine protected areas where controlled commercial and recreational fishing were allowed. Seventy-four percent of participants chose to protect areas using this type of management (lowest level of protection), and on average, participants allocated $66 \%( \pm 7.8 \% \mathrm{SE})$ of their cubes to this level of protection. Similarly, $74 \%$ of participants chose to protect some areas of the coast using the second level of protection where only non-extractive recreational activities were allowed. However, the average number of cubes allocated to this type of protection was lower than in the previous case as participants on average allocated $30 \pm 7.5 \%$ of the cubes to this level of management. Generally, participants did not support the full protection of areas of the marine environment, i.e. where no anthropogenic activities would be permitted. Only 4 participants chose to implement the highest form of protection in certain areas of the coast. Interestingly, these areas were of very restricted size as participants who chose the highest level of protection allocated on average only 2 cubes to this type of management.

Digital maps that represented the distribution of high, medium and low protection areas as chosen by the participants were created (Fig. 4). According to 

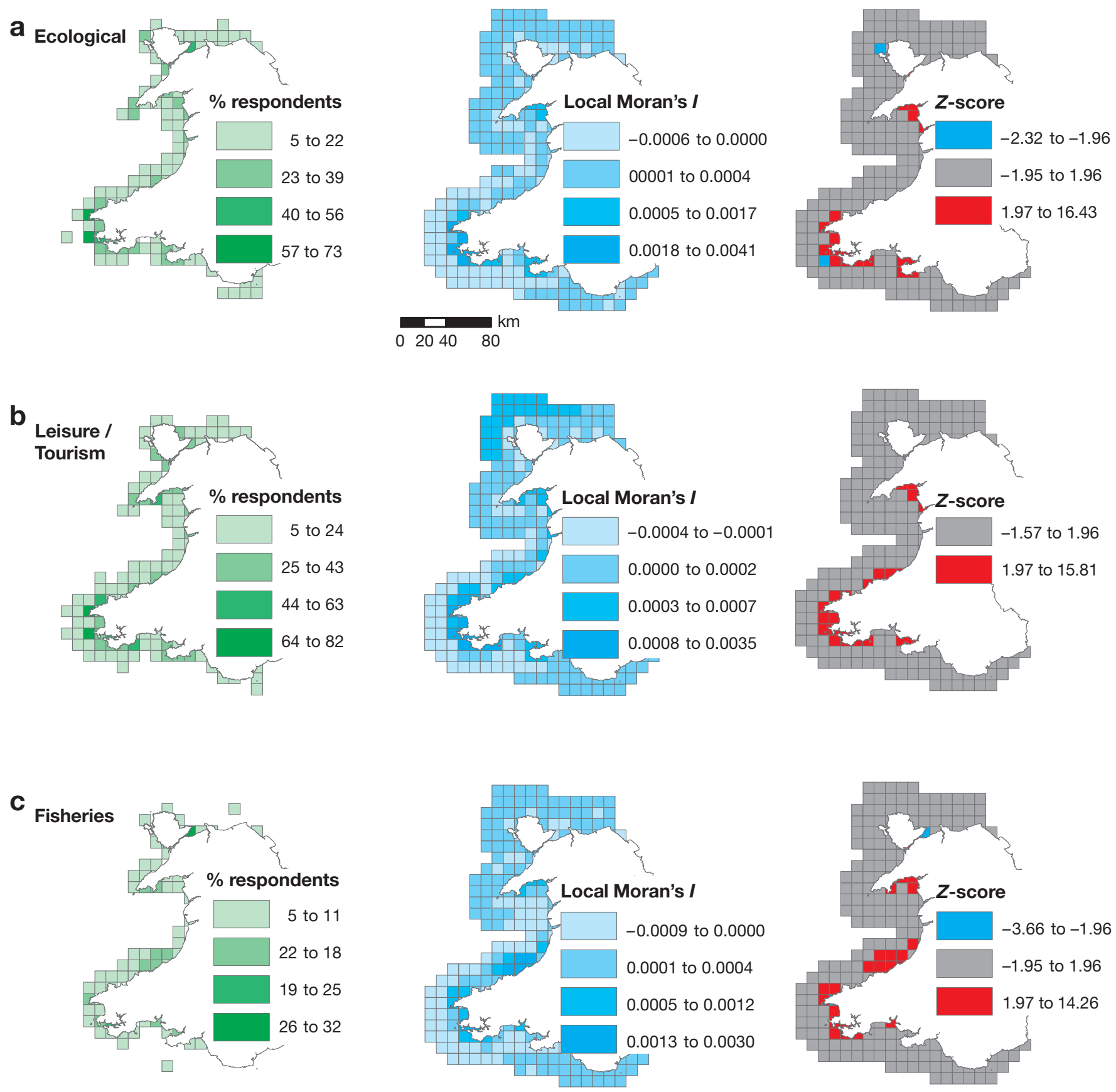

Fig. 2. (this and facing page). Spatial distribution of (a) ecological, (b) leisure, (c) fisheries, (d) identity/heritage, (e) industrial, and (f) energy benefits identified by stakeholders around the Welsh coast. Left: \% of participants who identified a particular cell as providing a particular benefit; middle: Local Moran's $I$, where high values indicate clustering of similar values; right: $Z$-score, where red cells indicate significant clusters of similar values at the 0.05 significance level, blue cells indicate dispersion of values, and grey cells had non-significant values

participants, the locations of areas of high protection were selected due to the 'uniqueness' of the ecological environment in the case of north Wales, and due to the permanent presence of cetacean populations on the west coast of Wales. Some of the most frequently selected areas under medium protection were located in estuarine areas, which were perceived to be unique and important environments. Ramsey Island was also considered unique, as it supports hundreds of breeding pairs of seabirds and is also an important seal breeding colony (Fig. 1). Areas of low protection were mainly located around areas perceived as both ecolog- 

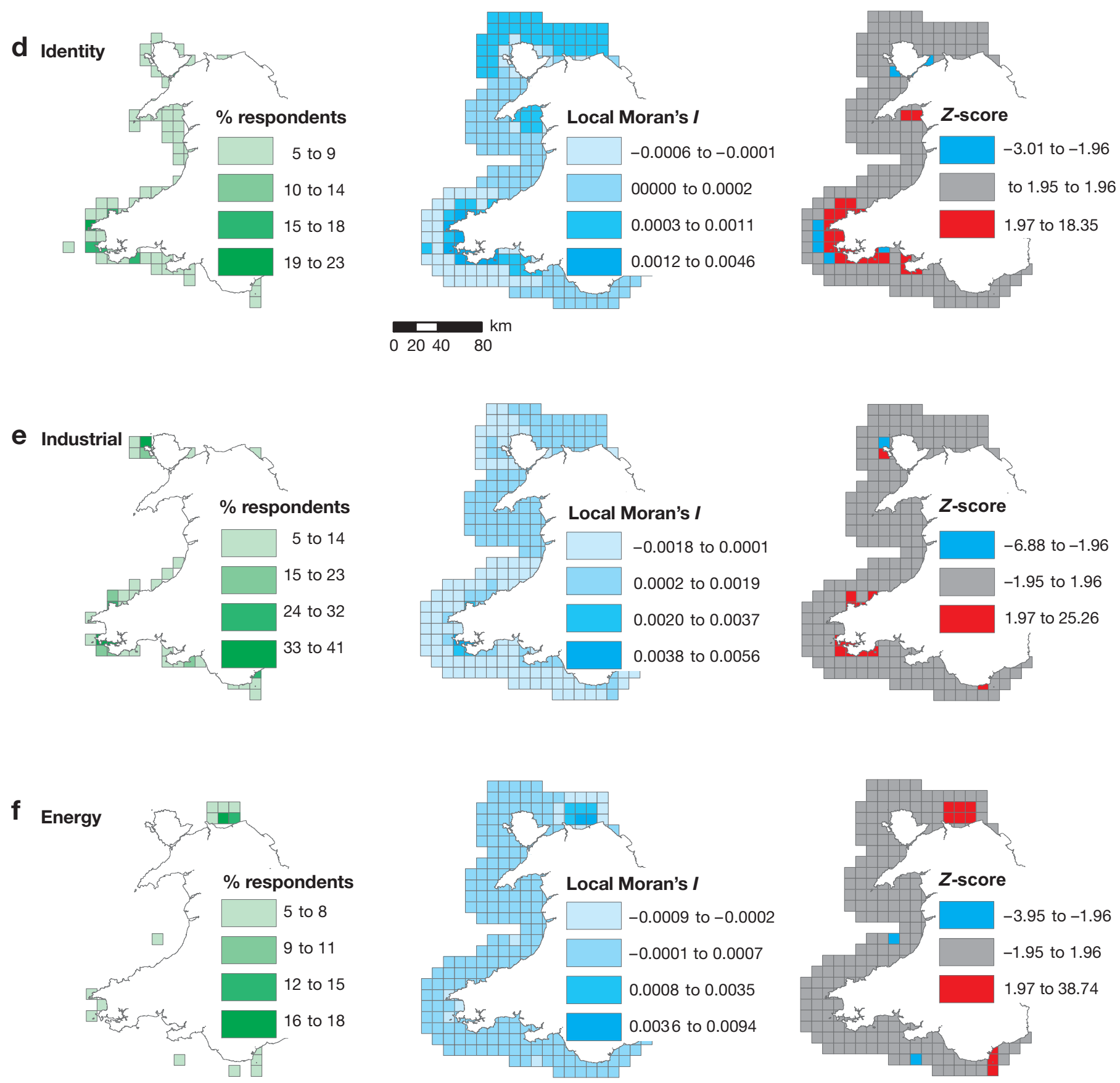

Fig. 2 (continued)

ically important and popular tourism destinations. In these areas, participants wanted to see low levels of restriction or codes of conduct that would mitigate the potential impacts derived from the presence of high densities of people.

Analysis of the data from the prioritisation exercise revealed that when participants were given the choice to select only 10 cells for protection, they mostly selected those cells with the highest ecological values
(Fig. 5a) while they tended to avoid those with associated industrial values (Fig. 5b). Cells selected for protection during the second and third subtasks had a lower ecological value than the first 10 selected cells. No differences were detected between the total number of values assigned to the cells selected in the first, second and third subtask (Fig 5a). Therefore, on the basis of this exercise it is possible to conclude that ecological value was prioritised over other values. 

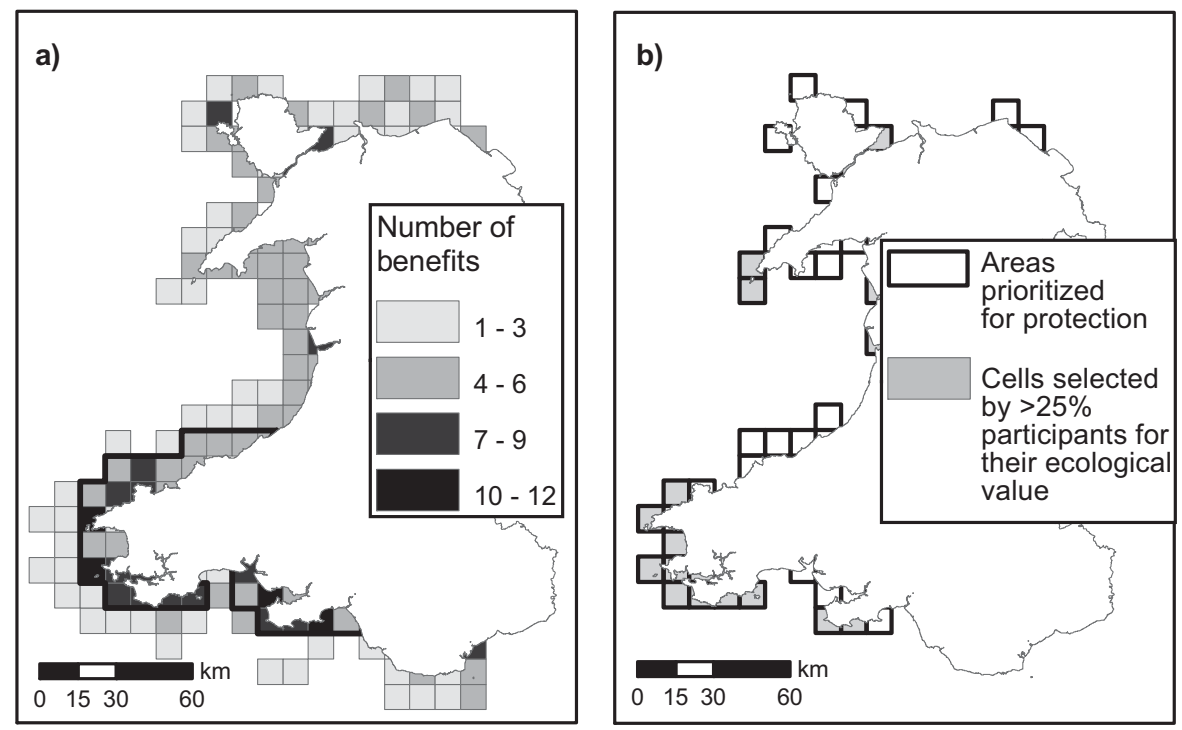

Fig. 3. (a) Total number of types of benefits/values allocated to each cell. Solid black line indicates significant clusters of similar numbers of values; (b) spatial overlap between cells selected for their ecological value by at least $25 \%$ of participants (grey cells) and those cells consistently selected for protection ( $>25 \%$ of participants) (solid black line)

Table 4. Pearson's correlation between pairs of benefits. ${ }^{*}$ correlation is significant at the 0.01 level

\begin{tabular}{|c|c|c|c|c|c|}
\hline & Leisure & Fisheries & Heritage & Industrial & Energy \\
\hline Ecological & $0.904^{*}$ & $0.702^{*}$ & $0.815^{*}$ & $0.422^{*}$ & 0.111 \\
\hline Leisure & - & $0.720^{*}$ & $0.801^{*}$ & $0.394^{*}$ & 0.120 \\
\hline Fisheries & & - & $0.526^{*}$ & $0.354^{*}$ & -0.309 \\
\hline Heritage & & & - & $0.413^{*}$ & 0.072 \\
\hline Industrial & & & & - & 0.019 \\
\hline
\end{tabular}

\section{Spatial overlap between protected areas and values}

Areas that were consistently selected for having 'ecological value' by at least $25 \%$ of the participants were overlaid over areas that were also consistently selected for protection; the spatial overlap between these areas was very high, as all ecologically important areas were selected for protection (Fig. 3b). Furthermore, a strong positive correlation was found between the number of times a cell was selected for its 'ecological value' and the number of times it was selected for protection $($ Pearson $=0.91, \mathrm{p}<0.001$ ). The high degree of spatial correlation between areas of protection and ecological importance suggests that participants did not allocate areas for protection at random.

Additionally, a positive correlation was found between the number of times a cell had been allocated 'ecological value' and the total number of values assigned to that same cell (Fig. 5c). This suggests that areas of perceived high ecological value were also considered to be important providers of other benefits.

\section{DISCUSSION}

\section{Distribution of stakeholder values}

Results from the study provide an insight into the range of values offered by the marine environment in the area of Wales. Many of the values considered in this paper are fundamentally economic in nature, i.e. their use enhances the financial resources and/or utility of users. Economic values have the scope to represent the different type of values placed on the environment (Gilpin 2000) and hence community values can also be part of economic values (Alvarez-Farizo \& Hanley 2006). In this paper, when we refer to community or stakeholder values, we are referring to the value that a particular stakeholder group accrues from the use of the environment. For example, commercial fishermen may receive greater economic value from commercial fish catches than from viewing a seascape, whereas the opposite may be true for recreational users of coastal regions. This study thus identifies the different reasons behind why particular areas are valued and provides a spatial representation of these values, 2 elements that are not generally captured through economic valuation.

The results indicated that stakeholders valued the Welsh coast for a variety of reasons. It is unlikely that the values identified here are unique to Wales and hence the findings are likely to be applicable to other rural coastal economies. Fourteen different types of 'values' were identified in the study region. All values included in the Beaumont et al. (2007) adaptation of the MEA were mentioned by participants. Addition- 
a)

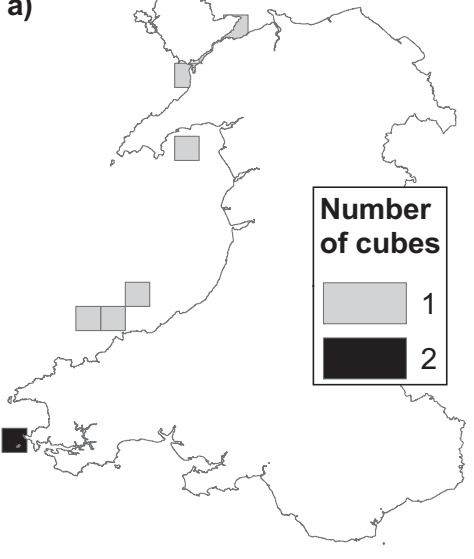

b)

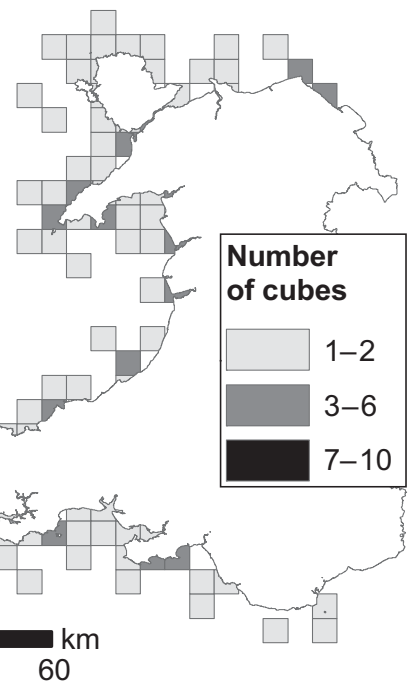

c)

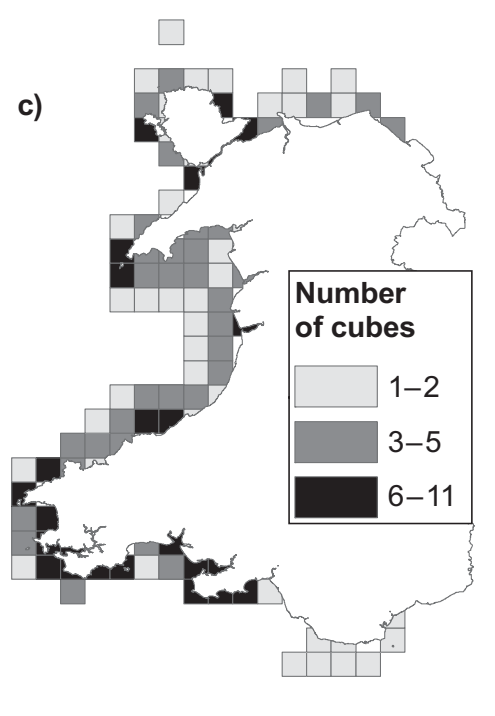

Fig. 4. Aggregated data for areas selected under different marine protected area (MPA) management regimes; (a) high level of protection, (b) medium level of protection, (c) low level of protection. Number of cubes refers to the cumulative number of cubes placed on that particular cell by all participants (see 'Materials and methods-Mapping of stakeholder values' for details)

ally, participants expanded on the MEA-based typology of values and included extra aspects such as geological values or more anthropogenic orientated aspects such as values related to areas of high population densities.

The spatial distribution of values varied across the study region. The data suggest that particular values followed a similar spatial distribution along the coast, as indicated by the strong positive correlations found between some pairs of values. Furthermore, it was apparent that some areas were perceived as more valuable than others in terms of the societal values derived from the marine environment. The spatial analysis of the distribution of values highlighted the presence of clear clusters of areas that were perceived as providers of multiple values. From a societal perspective, these zones or 'hotspot areas' are important locations where multiple interests overlap and will require higher levels of stakeholder involvement in prospective spatial management plans, particularly in cases of conflicting values (e.g. ecological value versus fisheries). Additionally, from a managerial point of view, the superimposition of these layers of information allows for the creation of multiple criteria maps which facilitate the identification of areas better suited for specific uses or management regulations. A similar methodology was used in a land-based case study to identify areas of agreement and disagreement in stakeholder landscape values, and a system was developed to rank potential land use for consistency with
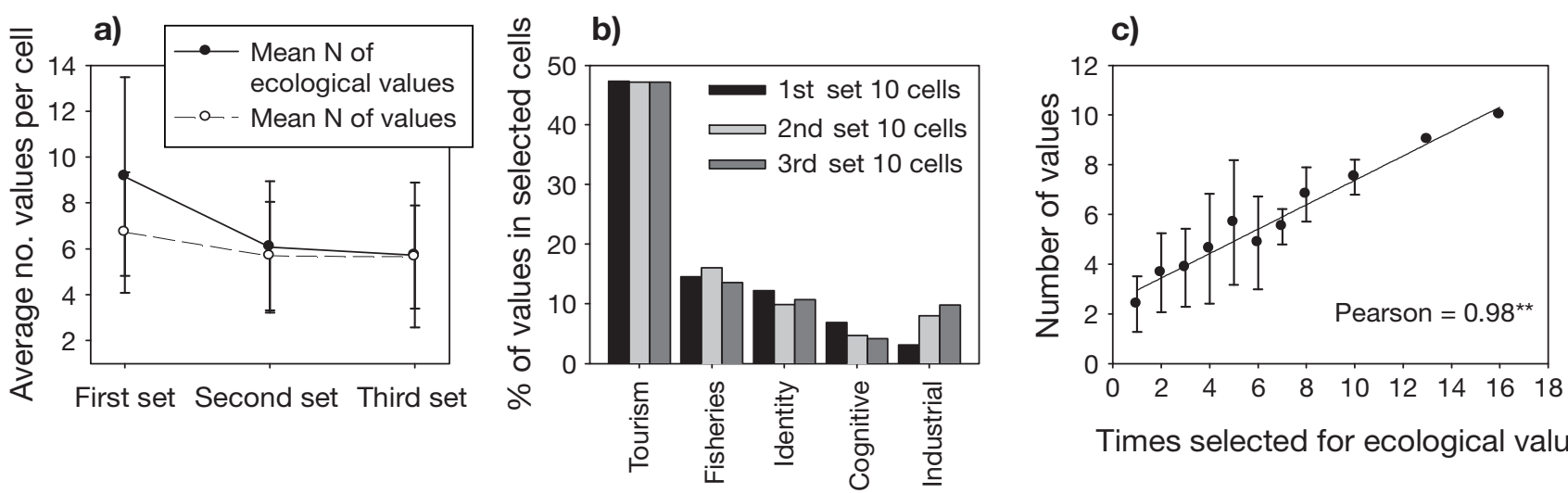

Times selected for ecological value

Fig. 5. (a) Solid circles represent the average number of times the cells selected in the first, second and third subtasks had been allocated 'ecological value'; open circles indicate the average number of values associated with the cells selected in the first, second and third subtasks. (b) Percentage of times the cells selected in the first, second and third subtasks had been allocated a particular 'value'. (c) Relationship between the number of times a cell had been selected due to its 'ecological value' and the total number of different 'values' allocated to that same cell. See 'Materials and methods-Mapping of stakeholder values' for details on the subtasks 
stakeholder values (Brown 2004). Another example of the application of suitability maps can be found in the planning process of a national forest in Canada, where a suitability analysis method was developed to map landscape values to determine the consistency of potential forest management strategies with communityheld landscape values (Reed \& Brown 2003).

Care has to be taken when interpreting the outcomes of this type of exercise, as location-specific valuations are strongly influenced by the subjective judgement and personal views of respondents, which will depend on the understanding of the respondents' definition of value, their experiences, familiarity with the area and their map literacy, among others (Zhu et al. 2010). Further limitations of this type of analysis include the ambiguous placement on the map of the cubes used in the exercise, where the area being mapped is actually smaller or bigger than the cube area used here, and the erroneous arrangement or incomplete placement of cubes by participants who are less familiar with the study area (Brown 2004). In our study, a few of the participants stated that they were more knowledgeable about their surrounding area of residence than about the rest of the study region. However, the comparison of the spatial distribution of stakeholder values with ecosystem services of known distribution (i.e. tourism, recreation, food and energy provision) confirmed the validity of stakeholder perceptions. Further evidence backing the soundness of stakeholder views comes from other studies which have previously confirmed the agreement between values and the assessment of geographic features (Brown 2004), conservation priorities (Raymond \& Brown 2006) and measures of ecological richness (Alessa et al. 2008).

\section{Location and management of MPAs}

The vast majority of stakeholders' representatives was not in favour of the establishment of MPAs which would completely exclude anthropogenic activities from within their boundaries. Conversely, most participants supported the implementation of MPAs with low levels of restriction where most activities would be allowed but would be adequately regulated. However, it is likely that a higher number of more restrictive areas would have been chosen during the exercise if the method of area selection had allowed for the selection of smaller areas, as it was mentioned by participants that the methodology used in the study forced them to choose highly protected MPAs of a minimum size patch of $100 \mathrm{~km}^{2}$ which they thought would significantly impact certain sectors of society. In future studies it may be advisable to adopt a different approach which enables participants to delineate their selected areas more accurately.
The selection frequency map for the location of MPAs provides an extra layer of information to managers and decision-makers in terms of which areas stakeholders consider should be protected. It is unquestionable that for MPAs to be successful in achieving their conservation goals, they must be designed with biological principles as primary design criteria (Roberts et al. 2003). However, information derived from the distribution of values and stakeholder views on the preferred location of MPAs could provide practical input in cases where decisions have to be made between 2 or more ecologically important sites. Here, stakeholder information could help discern which site would be less controversial to protect from a societal point of view. Additionally, it has been suggested that the involvement of stakeholders in management plans is likely to increase the quality and durability of environmental decisions (Beierle 2002, Reed 2008), as well as increasing the likelihood that decisions are perceived to be more holistic and fairer, as they account for a wide range of different values and needs (Richards et al. 2004).

In Wales, the Welsh Assembly Government is currently identifying and designating a network of marine conservation zones (MCZs), taking into account social, economic and ecological criteria. Whilst some areas of the MCZs will have management regimes that will be directed towards the maintenance of conservation status by allowing existing activities to continue if they do not cause site conditions to deteriorate, other areas will be designated as Highly Restricted MCZs, which will include a general presumption against fishing of all kinds, all constructive, destructive and disturbing activities. Therefore, the methodology and information provided in this study can contribute towards the identification of areas better suited for particular management regimes from a social perspective.

Graphical representations of values, including maps, can have a powerful influence in decision-making; thus care is needed to ensure that their use reflects the quality of information they represent. We investigated the values of different stakeholder groups through interviews with 2 representatives of each group. Although the resulting maps appear to be sensible, we recommend that future studies include higher numbers of people in the interviews to allow the investigation of variations in opinion within and between the different groups. Furthermore, attention has to be paid to the potential disproportional representation of interest sectors, in which case weightings might need to be applied to the final valuation maps.

Although some concerns have been raised regarding the quality of stakeholder-based environmental decisions, a review carried out in 2002 on the effects of stakeholder participation on the quality of environmental decisions determined that there is evidence that 
stakeholders contribute with new information and ideas to the decision process (Beierle 2002). Therefore, stakeholder participation can enhance the quality of environmental decisions by considering more comprehensive information inputs. Similar conclusions can be drawn from our study, as the results indicate that participants tended to protect ecologically important areas while at the same time avoiding areas where restrictions could have an impact on society, such as important areas for industrial activities. This suggests that stakeholders tried to balance conservation needs with social demands.

In this study, we adapted a methodology previously used on terrestrial environments to map stakeholders' values of the marine environment. The mapping exercise provided key information on the distribution of stakeholder values and the preferred distribution of MPAs in Wales. The outcomes of this study will facilitate the integration of social values with environmental and economic data to provide a more comprehensive understanding of the complexities and dynamics of socio-ecological systems. Although this study focuses on the Welsh coast, the approach used here to map stakeholder values could be used in coastal systems elsewhere to provide practical data to inform successful marine spatial planning which takes into account social, ecological and economic factors.

Acknowledgements. We thank all respondents for their participation and help. We also thank H. Hinz and 2 anonymous reviewers for useful comments and suggestions. This work forms part of a $\mathrm{PhD}$ studentship funded jointly by the Economic and Social Research Council and the Natural Environment Research Council of the United Kingdom (grant number ES/F009801/01).

\section{LITERATURE CITED}

Alessa L, Kliskey A, Brown G (2008) Social-ecological hotspots mapping: a spatial approach for identifying coupled social-ecological space. Landsc Urban Plann 85:27-39

Alvarez-Farizo B, Hanley N (2006) Improving the process of valuing non-market benefits: combining citizens' juries with choice modelling. Land Econ 82:465-478

> Beaumont NJ, Austen MC, Atkins JP, Burdon D and others (2007) Identification, definition and quantification of goods and services provided by marine biodiversity: implications for the ecosystem approach. Mar Pollut Bull 54: 253-265

Beierle TC (2002) The quality of stakeholder-based decisions. Risk Anal 22:739-749

Brown G (2004) Mapping spatial attributes in survey research for natural resource management: methods and applications. Soc Nat Resour 18:17-39

Brown G, Reed P (2000) Validation of a forest values typology for use in national forest planning. For Sci 46:240-247

Bryan BA, Raymond CM, Crossman ND, Macdonald DH (2010) Targeting the management of ecosystem services based on social values: where, what, and how? Landsc Urban Plann 97:111-122

CBD (Convention on Biological Diversity) (2008) Conference of the parties to the Convention on Biological Diversity (COP9), decision IX/20: Marine and coastal biodiversity. Available at www.cbd.int/decision/cop/?id=11663

Cowling RM, Egoh B, Knight AT, O'Farrell PJ and others (2008) An operational model for mainstreaming ecosystem services for implementation. Proc Natl Acad Sci USA 105: 9483-9488

DEFRA (Department for Environment and Rural Affairs) (2009) Marine and coastal access act 2009. Department for Environment and Rural Affairs. Available at www. legislation.gov.uk/ukpga/2009/23/pdfs/ukpga_20090023_ en.pdf (accessed November 2010)

Gilpin A (2000) Environmental economics: a critical overview. John Wiley \& Sons, Chichester

McIntyre N, Moore J, Yuan M (2008) A place-based, valuescentered approach to managing recreation on Canadian crown lands. Soc Nat Resour 21:657-670

MEA (Millennium Ecosystem Assessment) (2005) Ecosystems and human well-being: a Framework Working Group for Assessment report of the Millennium Ecosystem Assessment. Island Press, Washington, DC

Mitchell A (2005) The ESRI guide to GIS analysis. Vol 2: spatial measurements and statistics. ESRI Press, Redlands, CA

> Moore J, Balmford A, Allnutt T, Burgess N (2004) Integrating costs into conservation planning across Africa. Biol Conserv 117:343-350

Naidoo R, Balmford A, Costanza R, Fisher B and others (2008) Global mapping of ecosystem services and conservation priorities. Proc Natl Acad Sci USA 105:9495-9500

OSPAR Commission (2003) OSPAR Recommendation 2003/3 on a network of marine protected areas. Available at www. ospar.org/documents/DBASE/DECRECS/Recommendations/ or03-03e.doc

> Raymond C, Brown G (2006) A method for assessing protected area allocations using a typology of landscape values. J Environ Plann Manag 49:797-812

> Raymond CM, Bryan BA, MacDonald DH, Cast A, Strathearn S, Grandgirard A, Kalivas T (2009) Mapping community values for natural capital and ecosystem services. Ecol Econ 68:1301-1315

> Reed MS (2008) Stakeholder participation for environmental management: a literature review. Biol Conserv 141: $2417-2431$

Reed P, Brown G (2003) Values suitability analysis: a methodology for identifying and integrating public perceptions of forest ecosystem values in national forest planning. J Environ Plann Manage 46:643-658

Richards C, Blackstock KL, Carter CE (2004) Practical approaches to participation. Socio-Economic Research Group (SERG) Policy Brief No. 1. Macaulay Land Use Research Institute, Aberdeen

Roberts CM, Andelman S, Branch G, Bustamante RH and others (2003) Ecological criteria for evaluating candidate sites for marine reserves. Ecol Appl 13:199-214

Tyrvainen L, Makinen K, Schipperijn J (2007) Tools for mapping social values of urban woodlands and other green areas. Landsc Urban Plann 79:5-19

UN (United Nations) (2002) Report of the world summit on sustainable development, Johannesburg, South Africa, 26 August - 4 September 2002. United Nations, New York, NY. Available at http://daccess-dds-ny.un.org/doc/UNDOC/ GEN/N02/636/93/PDF/N0263693.pdf?OpenElement (accessed November 2010)

Zhu X, Pfueller S, Whitelaw P, Winter C (2010) Spatial differentiation of landscape values in the Murray River region of Victoria, Australia. Environ Manag 45:896-911

> Zube EH (1987) Perceived land use patterns and landscape values. Landscape Ecol 1:37-46 